$\mathrm{DOE} / \mathrm{ER} / 13544--\mathrm{T} 4$

DE93 011265

\title{
LASER SPECTROSCOPY AND DYNAMICS OF TRANSIENT SPECIES
}

\author{
Progress Report
}

June 1, 1992 - May 31, 1993

Dennis J. Clouthier

Department of Chemistry

University of Kentucky

Lexington, KY 40506-0055

\section{DISCLAIMER}

\begin{abstract}
This report was prepared as an account of work sponsored by an agency of the United States Government. Neither the United States Government nor any agency thereof, nor any of their employees, makes any warranty, express or implied, or assumes any legal liability or responsibility for the accuracy, completeness, or usefulness of any information, apparatus, product, or process disclosed, or represents that its use would not infringe privately owned rights. Reference herein to any specific commercial product, process, or service by trade name, trademark, manufacturer, or otherwise does not necessarily constitute or imply its endorsement, recommendation, or favoring by the United States Government or any agency thereof. The views and opinions of authors expressed herein do not necessarily state or reflect those of the United States Government or any agency thereof.
\end{abstract}

February 1993

PREPARED FOR THE U. S. DEPARTMENT OF ENERGY UNDER GRANT NUMBER DE-FG05-86ER13544 


\section{Progress Report}

Progress on the research program for this grant has been steady. A postdoctoral associate, Dr. J. Karolczak, has been supported by the grant since it started in June, 1992. Dr. Karolczak has previously been employed in my laboratory and is a productive hardworking researcher. I have two graduate students finishing their Ph. D. theses on various aspects of the DOE research. Two new students have recently joined my group and will be working on new DOE projects.

Our work on the sub-Doppler spectroscopy of thioformaldehyde is now reaching completion. A paper entitled "A spectroscopic view of internal conversion in a small polyatomic molecule: Sub-Doppler intracavity dye laser spectroscopy of thioformaldehyde" has been published in The Journal of Chemical Physics, 97, 1630 (1992) and another paper will be submitted to the same journal in the near future. In this work we have shown that sub-Doppler structure in the $\mathrm{H}_{2} \mathrm{CS}$ spectrum correlates with our previous observations of anomalously long fluorescence lifetimes and reduced quantum yields of fluorescence under collision-free conditions. Extensive measurements of the sub-Doppler spectrum have been used to refine the ground and excited state constants and map out the very extensive $S_{1}-T_{1}$ and $S_{1}-S_{0}$ perturbations in the excited state. The singlet-triplet perturbations are found to be large, with matrix elements of $0.05-0.2$ $\mathrm{cm}^{-1}$ and occur haphazardly when levels in the two states are in near-coincidence. The singletsinglet perturbations have much smaller matrix elements $\left(0.01-0.001 \mathrm{~cm}^{-1}\right)$ and involve more than half the upper state levels. We have not found any correlation between the extent of the perturbations and the upper state quantum numbers $J$ or $K_{2}$.

We have recorded extensive high resolution FTIR spectra of many bands of $\mathrm{HCOCl}$ and DCOCl. A complete analysis of the $v_{3}$ bands of $\mathrm{HCO}^{35} \mathrm{Cl}$ and $\mathrm{HCO}^{37} \mathrm{Cl}$ has been written up and submitted to the Journal of Molecular Spectroscopy. This is the first high resolution FTIR study of formyl chloride, a transient molecule which readily decomposes to give $\mathrm{HCl}$ and $\mathrm{CO}$. In further work we have also analyzed the $v_{3}$ band of DCOCl and the $v_{2}$ and $2 v_{6}$ bands of $\mathrm{HCOCl}$. 
In the latter $\mathrm{HCOCl}$ bands extensive perturbations have been found which give a detailed view of Coriolis and Fermi interactions in the excited vibrational states. The analysis of the $v_{4}$ bands of $\mathrm{DCOCl}$ and $\mathrm{HCOCl}$ is now in progress.

Laser induced fluorescence experiments on formic acid $(\mathrm{HCOOH})$ are in progress. We have shown that it is possible to obtain jet spectra of formic acid monomers by pyrolysis of the dimeric hydrogen bonded species. High resolution continuous jet spectra at a rotational temperature of about $10 \mathrm{~K}$ have been recorded. We are now attempting to obtain colder spectra using a heated pulsed valve.

We have been exploring the use of a technique termed reactive jet spectroscopy for the production of new reactive intermediates. In this method, we use exothermic reactions of $\mathrm{F}_{2} / \mathrm{Ar}$ gas streams with substrate materials to produce the transient molecule. At the beginning of this grant period we had obtained a new LIF spectrum in the visible which we had tentatively attributed to the $\mathrm{SF}_{2}$ species. Subsequent work has shown that the spectrum is not due to $\mathrm{SF}_{2}$, but is most likely that of the $\mathrm{FS}_{2}$ free radical, a previously unknown species. Support for this interpretation comes from our own $a b$ initio calculations which predict ground and excited state vibrational frequencies, the electronic excitation energy and rotational constants which are in excellent agreement with the experimental data. We have obtained high resolution jet spectra of $\mathrm{FS}_{2}$ using a single mode ring laser and have partially analyzed the rotational structure. The bands of type-C, consistent with the assignment of the transition as $\tilde{A}^{2} \mathrm{~A}^{\prime \prime}-\tilde{\mathrm{X}}^{2} \mathrm{~A}^{\prime \prime}$ and there are clearly resolved spin splittings in the spectra. We hope to complete the analysis of these spectra and publish the results in the next six months.

We have begun preliminary experiments on the $S_{3}$ and $S_{4}$ systems. The initial experiments consisted of vaporization of $\mathrm{S}_{8}$, entraining it in argon, passing it through the heated zone of the pyrolysis jet and searching for the LIF spectra. To date, these experiments have been unsuccessful. 


\section{Research Outline For The Next Year}

We are nearing completion of the construction of our time-of-flight mass spectrometry system which will be used for optimization of jet conditions and REMPI studies of nonfluorescent species. In the next year we expect to have this device operational and productive.

This summer I will be travelling to Anthony Merer's laboratory at the University of British Columbia to record FTIR spectra of more bands of $\mathrm{HCOCl} / \mathrm{DCOCl}$ and to initiate studies of sulfine $\left(\mathrm{H}_{2} \mathrm{CSO}\right)$. We have observed the latter in low resolution FTIR studies of the pyrolysis products of dimethyl sulfoxide (DMSO) and the dimer of sulfine, which we have synthesized.

A major effort will be made in the next year to obtain very cold jet spectra of formic acid so that a thorough rotational analysis can be done. Simulations have shown that a rotational temperature of about $3 \mathrm{~K}$ will be necessary for the analysis and this should not be difficult to attain once we get our heated pulsed jet working.

We anticipate beginning LIF studies of the jet spectrum of formyl chloride this summer. We have shown that $\mathrm{HCOCl}$ does fluoresce weakly but have yet to attempt to observe the jet spectrum. Our approach will be to use a heterogeneous reaction between formic acid vapor and granular phosphorus pentachloride in the throat of the jet to produce formyl chloride. We have used similar techniques to study $\mathrm{S}_{2} \mathrm{O}$ in the past. 

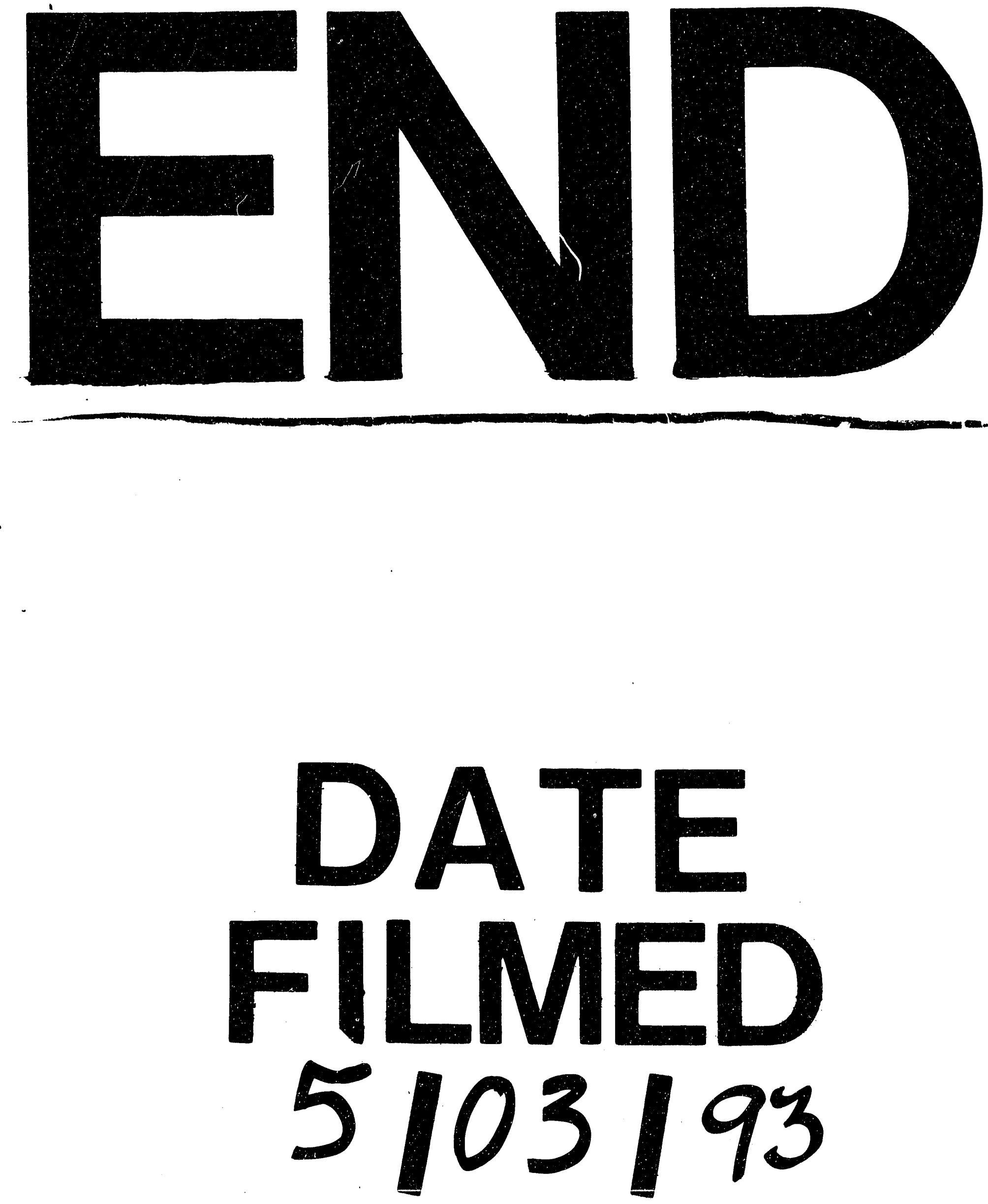
